\title{
Paraneoplastic Cerebellar Degeneration: Successful Early Detection and Treatment of Cancer through Characterization of the Anti-Purkinje Cell Antibody
}

\author{
Keiko Tanaka, Shuichi Igarashi, Motoyoshi Yamazaki, Takashi Nakajima, \\ Tadashi MIYATAKE* and Koichiro SAKAI**
}

\begin{abstract}
Paraneoplastic cerebellar degeneration (PCD) is thought to be caused by an autoantibody against both tumor and neuronal tissue. Such autoantibodies are most frequently detected in patients with gynecological or breast cancer, and are designated as anti-Yo. We report here a patient with PCD whose underlying cancer could not be detected despite extensive tumor survey. IgG in her serum and cerebrospinal fluid reacted with the cytoplasm of cerebellar Purkinje cells immunohistochemically. On immunoelectron microscopy, the endoplasmic reticulum and Golgi complex were stained. Her IgG bound to the $58 \mathrm{kD}$ band on immunoblots of cerebellar proteins. A reaction was also observed with the recombinant proteins deduced from the complementary DNA clone encoding a neuronal cell antigen reported by Sakai et al (Ann Neurol 28: 692, 1990). Based on these results, successful early resection of fallopian tube adenocarcinoma was performed. It is crucially important to characterize these PCD related autoantibodies for the early treatment of underlying malignant tumors.
\end{abstract}

(Internal Medicine 31: 1339-1342, 1992)

Key words: fallopian tube adenocarcinoma, anti-Yo, immunohistochemistry, immunoblot

\section{Introduction}

Paraneoplastic cerebellar degeneration (PCD) is a rare disorder known to represent a remote effect of cancer (1). Small cell lung cancer is the most frequent neoplasm amongst those causing PCD; gynecological cancers, breast cancers or lymphomas are also frequent underlying tumors (2). The precise etiology of the paraneoplastic syndrome is unknown. However, there is increasing evidence to support the involvement of immunological mechanisms (3-7). Anti-Purkinje cell antibodies are frequently detected in the serum and cerebrospinal fluid (CSF) of patients with gynecological or breast cancers. These antibodies are designated as anti-Yo, which reacts with the cytoplasm of Purkinje cells immunohistochemically and reacts with the $62 \mathrm{kd}$ and $34 \mathrm{kd}$ bands on immunoblots (8). We describe here a patient with PCD in whom no underlying tumor could be detected despite extensive exploration, however her serum and CSF were shown to contain high titers of antibody similar to anti-Yo. Test laparotomy revealed a fallopian tube tumor of $2 \mathrm{~cm}$ in diameter, and tumor resection resulted in improvement of cerebellar ataxia.

\section{Materials and Methods}

\section{Patient}

A 70-year-old woman was in good health until June 15, 1990, when diplopia appeared. Within 3 days, she developed ataxia, vertigo, nausea and vomiting. Her speech and gait disturbance due to cerebellar ataxia worsened rapidly and finally she became bedridden at the beginning of July. She was admitted to a local hospital and was transferred to our hospital on September 28, 1990. Examinations proved unremarkable for the general organs.

On neurological examination, she showed saccadic eye movement and down-beat nystagmus, together with slurred and unclear speech. She had mild weakness of the proximal limb muscles. She displayed marked limb

\footnotetext{
From the Department of Neurology, Brain Research Institute, Niigata University, Nigata, *the Department of Neurology, Faculty of Medicine, Tokyo Medical and Dental University, Tokyo, and **the Department of Neurology, Kanazawa Medical University, Kanazawa Received for publication June 17, 1992; Accepted for publication October 19, 1992

Reprint requests should be addressed to Dr. Keiko Tanaka, the Department of Neurology, Brain Research Institute, Niigata University, Asahimachi-Dori, Niigata 951, Japan
} 
and truncal ataxia which prevented her from sitting unaided. Myoclonus was observed on her right arm. The deep tendon reflexes were hyperactive in the upper extremities but decreased at the patella tendons. The patient also showed dysuria due to atonic bladder. Blood analysis was normal except for a slight elevation of LDH (490 IU/1). Tumor markers, CEA, $\alpha$-fetoprotein, CA19-9 and CA125, were all normal. Her CSF contained $45 / \mathrm{mm}^{3}$ mononuclear cells, $86 \mathrm{mg} / \mathrm{dl}$ glucose and $59 \mathrm{mg} / \mathrm{dl}$ protein with an $\mathrm{IgG}$ content of $8.4 \mathrm{mg} / \mathrm{dl}$. A cranial CT scan and MRI were normal except for a small old cerebellar infarction. A lung CT, abdominal CT, intrapelvic $\mathrm{CT}$, abdominal echogram, fiberscopy of the upper and lower gastrointestinal tract, vesicography and gynecological examinations revealed no evidence of tumors. An electromyogram showed mild neurogenic changes in the rectus femoris and anterior tibial muscles with no evidence of neuromuscular block.

\section{Detection of the anti-neuronal antibodies}

Normal tissues (cerebrum, cerebellum, spinal cord, liver, kidney and heart muscle) were obtained from autopsied men or from rats and mice. They were snap frozen in liquid nitrogen to prepare cryostat sections or homogenized for electrophoresis. Some of the materials were fixed in $4 \%$ paraformaldehyde for 12 hours and embedded in paraffin for immunohistochemical use. Samples of the patient's serum and CSF were taken several times before and after tumor resection. The procedures for immunohistochemistry or immunoblotting were as in previous reports with some modifications $(7,9)$. For further characterization, the recombinant proteins were produced from the complementary DNA (cDNA) clone encoding a $52 \mathrm{kd}$ protein recognized by an antineuronal cell antibody in the serum from a patient with PCD (designated as pWR590-PCD17SN) (10) for immunoblot. Immunoelectron microscopy was performed according to the procedure described previously (11).

\section{Results}

Immunohistochemistry showed that the patient's IgG from serum and CSF reacted with Purkinje cell cytoplasm (Fig. 1), but it did not react with other tissues in the central nervous system (CNS) or general organs outside the CNS, at dilutions of $1: 100$ to $1: 40,000$ and $1: 5$ to 1:400, respectively. On immunoblot, the patient's IgG from serum and CSF reacted with the $58 \mathrm{kd}$ band (Fig. 2a). On immunoelectron microscopy, the endoplasmic reticulum and Golgi apparatus were stained with the patient's serum (data not shown). They also reacted with the $58 \mathrm{kd}$ cerebellar protein, also with the $45 \mathrm{kd}$ band on blots of recombinant proteins from $\mathrm{pWR} 590-\mathrm{PCD} 17 \mathrm{SN}$ clones but not with blots of pWR590 vectors without inserts (Fig. 3). These results and the patient's clinical features were strongly suggestive of PCD with an auto-

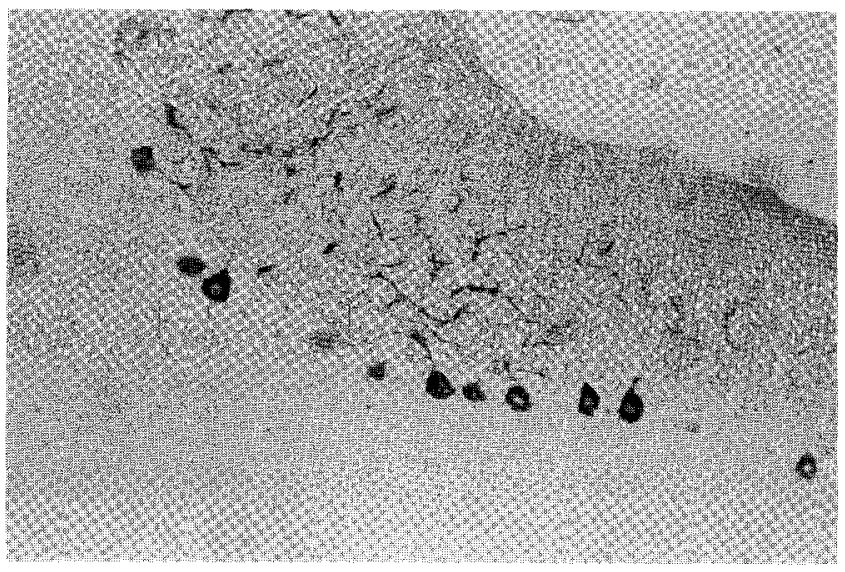

Fig. 1. Paraformaldehyde-fixed paraffin-embedded section of normal human cerebellum overlaid with patient CSF at a dilution of $1: 100$ and stained using biotin-avidin immunoperoxidase method $(\times 500)$. The cytoplasm of Purkinje cells were stained.
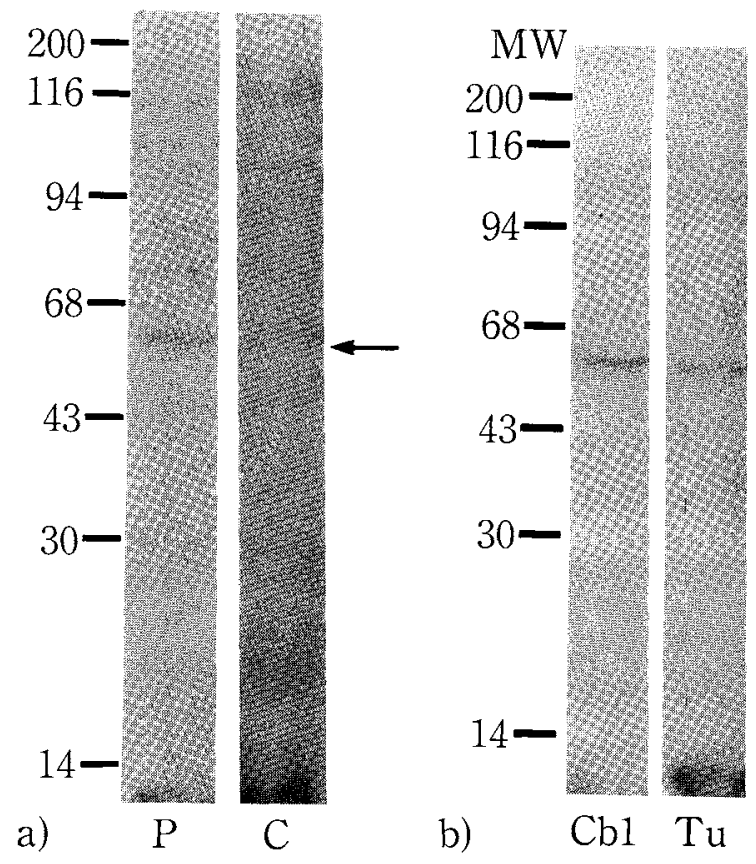

Fig. 2. a) Western blots of rat cerebellar homogenates incubated with the sera, diluted 1:250, from patient (P) and a normal subject (C). The patient's serum recognized a $58 \mathrm{kd}$ band. b) Western blots of rat cerebcllar homogenates $(\mathrm{Cbl})$ and the tumor tissue homogenates $(\mathrm{Tu})$ from the patient incubated with the patient's serum. The $58 \mathrm{kd}$ bands on both of the blots were stained.

antibody very similar to the anti-Yo antibody; her underlying tumor was thought to be gynecological or breast cancer. As breast cancer was not found by mammography or other examinations, laparotomy was undertaken to search for gynecological tumors; laparotomy confirmed that the patient had a fallopian tube tumor of $2 \mathrm{~cm}$ in diameter which was found to be undifferentiated adenocarcinoma (Fig. 4). Her serum also stained the $58 \mathrm{kd}$ 


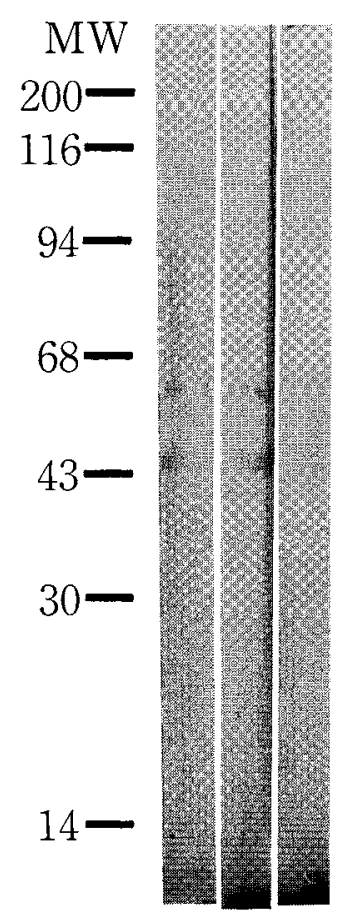

Fig. 3. Immunoblot analysis of recombinant proteins from pWR590-PCD17SN clones (two left lanes) and from $p W R 590$ vectors without inserts (right lane). The recombinant proteins were stained with the serum from the patient, but the vectors without inserts were not stained.

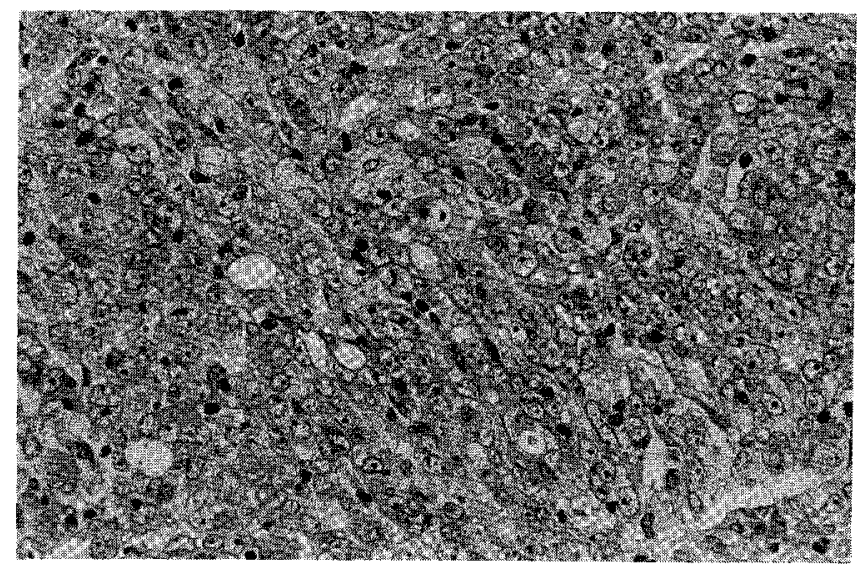

Fig. 4. Photomicrograph of the fallopian tube adenocarcinoma (HE stain, $\times 400)$.

band on blots of resected tumor tissue (Fig. 2b). The patient was given 3 cycles of FCAP therapy (cisplatin, adriamycin, cyclophosphamide and 5-fluorouracil). A month after tumor resection, her clinical symptoms improved and she has been able to enjoy rehabilitation in a wheelchair and to sit by herself. Her speech can also be understood more easily than before. The maximum dilution titer of her autoantibody has decreased to
$1: 5,000$ in her serum and $1: 100$ in her CSF.

\section{Discussion}

PCD is one of the paraneoplastic neurological syndromes encountered in patients with malignant tumors, showing rapidly progressive cerebellar ataxia associated with certain other neurological signs such as dementia, exaggerated deep tendon reflexes or limb weakness. The neuropathology of PCD is usually limited to the cerebellar cortex as a diffuse and extensive loss of Purkinje cells sometimes associated with infiltrative perivascular lymphocytes in the meninges and in the brain. Small cell lung cancer is the most frequent underlying cancer in PCD, however, detection of autoantibodies against Purkinje cells is not so common (8). Almost $50 \%$ of PCD patients with gynecological or breast cancer have antineuronal autoantibodies. The antibody called antiYo is a polyclonal $\mathrm{IgG}$ which labels the cytoplasm of Purkinje cells with a coarse granular appearance immunohistochemically; on immunoelectron microscopy, ribosomes, granular endoplasmic reticulum and Golgi complex have been shown to be stained (11). Anti-Yo reacts with the $62 \mathrm{kd}$ (CDR62) and $34 \mathrm{kd}$ (CDR34) bands on immunoblots of human Purkinje cell extracts (5). Anti-Yo antibody is found at high titers in both the blood and CSF of PCD patients. Its relative specific activity is higher in the CSF than in the serum, suggesting antibody synthesis in the CNS (12). The Yo antigen is also known to be expressed in tumor tissue from patients with anti-Yo positive PCD (13). Tsukamoto et al (14) reported 4 PCD patients ( 2 with uterine and 2 with ovarian cancer) whose sera reacted with Purkinje cell cytoplasm and other neurons throughout the CNS immunohistochemically, and reacted with the $52 \mathrm{kd}$ band on immunoblots. These findings suggest that gynecological or breast cancers may have a similar and stronger antigenicity compared to other tumors. The structure of the tumor antigens has been reported recently. A cDNA encoding an epitope of CDR34 was isolated which revealed that the CDR34 protein is composed of tandem repeats of six amino acid motifs (15). More recently, a cDNA encoding the major Yo antigen CDR62 has been shown to be a member of the family of leucine-zipper DNA binding proteins (16). Sakai et al (10) isolated a cDNA clone encoding a $52 \mathrm{kd}$ protein recognized by serum from the patients with $\mathrm{PCD}$ associated with uterine cancer reported by Tsukamoto et al (14), to which our patient's serum reacted as described above, and which has a very similar structure to that of CDR62. Sato et al (17) also reported the sequence analysis of a cDNA clone encoding a $58 \mathrm{kd}$ protein recognized by $\mathrm{PCD}$ serum which is similar to zinc finger proteins. The present patient displayed the typical clinical features of PCD and her serum and CSF contained antibody activity against the $58 \mathrm{kd}$ protein in the cytoplasm of Purkinje cells which 
labeled the endoplasmic reticulum and Golgi complex and reacted with recombinant proteins deduced from the cDNA encoding Yo antigen. These results led us to find her gynecological cancer, and early resection of the cancer was successfully performed. More than $50 \%$ of patients with PCD develop neurological disorders before any underlying tumor can be detected. It is very important therefore to characterize the autoantibodies in patients with paraneoplastic syndrome for the early treatment of malignant tumors.

Acknowledgements: We are grateful to Prof. K. Tanaka and Dr. S. Kodama of the Department of Obstetrics and Gynecology for performing the tumor operation and to Ms. M. Hirahara for technical assistance.

\section{References}

1) Brain R, Norris FH. The Remote Effect of Cancer on the Nervous System. Grune \& Stratton, New York, 1965, p. 185.

2) Anderson NE, Cunningham JM, Posner JB. Autoimmune pathogenesis of parancoplastic neurological syndromes. CRC Crit Rev Neurobiol 3: 245, 1987.

3) Grecnlee JE, Brashcar HR. Antibodies to cerebellar Purkinje cells in patients with parancoplastic cerebellar degeneration and ovarian carcinoma. Ann Neurol 14: 609, 1983.

4) Jaeckle KA, Graus F, Houghton A, ct al. Autoimmune response of patients with parancoplastic cercbellar degeneration to a Purkinje cell cytoplasmic protein antigen. Ann Neurol 18: 592, 1985.

5) Cunningham I, Graus F, Anderson N, et al. Partial charactcrization of the Purkinje cell antigens in parancoplastic cerebellar degeneration. Neurology 36: 1163, 1986.

6) Tanaka K, Yamazaki M, Sato S, et al. Antibodies to brain proteins in paraneoplastic cerebellar degencration. Neurology 36: $1169,1986$.
7) Tanaka K, Tanaka M, Miyatake $T$, et al. Antibodies to brain proteins in a patient with subacute cerebellar degeneration and Lambert-Eaton myasthenic syndrome. Tohoku J exp Med 153: $161,1987$.

8) Posner JB, Furneaux HM. Paraneoplastic syndromes. in: Immunologic Mechanisms in Neurologic and Psychiatric Disease. Waksman BH, Ed. Raven Press, New York, 1990, p. 187.

9) Sternberger LA. Immunocytochemistry 2nd edition, New York, Wiley, 1979.

10) Sakai K, Mitchell DJ, Tsukamoto T, et al. Isolation of a complementary DNA clone encoding an autoantigen recognized by an anti-neuronal cell antibody from a patient with paraneoplastic cerebellar degeneration. Ann Neurol 28: 692, 1990.

11) Rodrignez M, Truh LI, O'Neill BP, et al. Autoimmune paraneoplastic cerebellar degeneration: Ultrastructural localization of antibody-binding sites in Purkinje cells. Neurology 38: 1380, 1988.

12) Graus F, Segurado OG, Tolosa E. Selective concentration of anti-Purkinje cell antibody in the CSF of two patients with paraneoplastic cerebellar degeneration. Acta Neurol Scand 78: 210, 1988.

13) Furneaux HM, Rosenblum MK, Dalman $J$, et al. Selective expression of Purkinje-cell antigens in tumor tissue from patients with paraneoplastic cerebellar degeneration. N Engl J Med 322: 1844, 1990.

14) Tsukamoto $\mathrm{T}$, Yamamoto $\mathrm{H}$, Iwasaki $\mathrm{Y}$, et al. Antincural autoantibodies in patients with parancoplastic cerebellar degeneration. Arch Neurol 46: 1225, 1989.

15) Dropcho EJ, Chen YT, Posner JB, et al. Cloning of a brain protein identified by autoantibodies from a patient with paraneoplastic cerebellar degeneration. Proc Natl Acad Sci USA 84: 4552, 1987.

16) Fathallah-Shaykh H, Wolf S, Wong E, et al. Cloning of a leucinezipper protein recognized by the sera of patients with antibodyassociated paraneoplastic cerebellar degeneration. Proc Natl Acad Sci USA 88: 3451, 1991.

17) Sato $S$, Inuzuka $T$, Nakano $R$, et al. Antibody to a zinc finger protein in a patient with paraneoplastic cerebellar degeneration. Biochem Biophys Res Commun 178: 198, 1991. 